\title{
Evaluation Efficacy of HEART Score in Prediction of Major Advanced Cardiac Events in Patients with Chest Pain
}

\author{
Ehsan Bolvardi ${ }^{1}$, Pooya Raoufi ${ }^{2}$, Veda Vakili ${ }^{3}$, \\ Hasan Jahed Taherani ${ }^{4}$, Mina Movaffaghi ${ }^{5}$, \\ Mehran Bahramian $^{6}$ and Koorosh Ahmadi ${ }^{*}$ \\ ${ }^{1}$ Department of Emergency Medicine, Mashhad University of Medical Sciences, Mashhad, Iran. \\ ${ }^{2}$ Emergency Medicine Resident, Mashhad University of Medical Sciences, Mashhad, Iran. \\ ${ }^{3}$ Social medicine Specialist, Mashhad University of Medical Sciences, Mashhad, Iran. \\ ${ }^{4}$ Social medicine Resident, Mashhad University of Medical Sciences, Mashhad, Iran. \\ ${ }^{5}$ Mashhad University of Medical Sciences, Mashhad, Iran. \\ ${ }^{6}$ Department of Emergency Medicine, Alborz University of Medical Sciences, Karaj, Iran.
}

http://dx.doi.org/10.13005/bbra/2126

(Received: 02 February 2016; accepted: 04 April 2016)

\begin{abstract}
Chest pain is one of the most common reasons for admitting patients to the emergency room. The focus of the diagnostic process in chest pain patients at the emergency department is to identify both low and high risk patients for an acute coronary syndrome (ACS). Numerous risk prediction scores have been developed for fast and accurate risk stratification of chest pain in ED, like HEART score that a new ED Chest Pain risk stratification score. In this prospective cohort study, we aimed to evaluate efficacy of HEART score in prediction of 30 days major advanced cardiac events (MACE) in acute chest pain patients. A total of 100 unselected patients presented with acute chest pain at the cardiac emergency department of Emam Reza Hospital in Mashhad, from September 2015 until February 2016. The HEART score was assessed as soon as the first lab results and ECG were obtained. Endpoint was the occurrence of major adverse cardiac events (MACE) within 30 days. After 30-day follow-up, a total of 24 patients (24\%) reached one or more endpoints, AMI was diagnosed in 18 patients $(18 \%), 2$ patients $(2 \%)$ underwent percutaneous coronary intervention (PCI), One (1\%) had coronary artery bypass graft (CABG) surgery and $3(3 \%)$ died. Independent predictors of MACE included age $(P=$ 0.001). Hypertension was independent predictor of the combined end point only in female $(\mathrm{P}=0.006)$. Age and troponin were independent predictors of the combined end point in both gender (Age $\mathrm{P}=0.032$ and Tpi $\mathrm{P}=0.000$ ). The average HEART score in the no end point group was 5.42 and in the patients with at least one end point was $7.42(\mathrm{P}=0.000)$. In low HEART scores (points 0-3), risk of MACE was $0 \%$. In patients with HEART scores 4-6, MACE was diagnosed in $\mathbf{1 4 . 5 8 \%}$. In patients with high HEART scores (7-10), MACE occurred in $41.46 \%$. In our study with increasing point of HEART score: sensitivity decreased, specifity increased and Positive predictive value increased.The HEART score helps in making accurate decisions at the emergency room without the use of invasive procedure. The HEART score is an easy, quick and reliable predictor of outcome in acute chest pain patients. It facilitates communication between doctors, especially when discussing the use of limited resources for chest pain patients. In this conditions who have higher HEART score points, choices may appear clear. This analysis suggests that HEART score can identify ED patients with acute chest pain for early discharge, as attention to high risk patients for admission for clinical observation, appropriate treatment including noninvasive testing and/or invasive strategies.
\end{abstract}

Keywords: Acute Chest Pain, HEART score, Major Advance Cardiac Events.

\footnotetext{
* To whom all correspondence should be addressed. Tel.: 00989124806577;

E-mail: kooroshem@gmail.com
} 


\section{Background}

Chest pain is one of the most common reasons for admitting patients to the emergency room. It has a wide range of etiologies including urgent diagnoses (i.e. acute coronary syndrome (ACS), pulmonary embolism, aortic dissection) and non-urgent diagnoses (i.e. musculoskeletal pain, gastroesophageal reflux disease (GERD), pericarditis).

An acute coronary syndrome (ACS) needs to be distinguished from a variety of other cardiac and non-cardiac diseases that cause chest pain. In certain cases, a diagnosis can be made quickly, in particular in the case of an acute transmural myocardial infarction. Non-ST-elevation ACS (nTEACS), previously called unstable angina or pending infarction, typically causes uncertain ${ }^{1}$, ${ }^{2}$. This diagnosis can be made quickly in case of concurrent typical changes in the electrocardiogram (ECG) and/or increased levels of myocardial markers in plasma.

Absence of such abnormalities, however, does not always exclude an nSTE-ACS. Therefore, excluding the diagnosis of nSTE-ACS is felt to be hard in the early stages of the diagnostic process. It is important to make a quick diagnosis as patients benefit significantly from early treatment ${ }^{3}$. In addition, a missed diagnosis may result in a wrongful discharge and ultimately in out of hospital sudden death when unstable angina becomes a myocardial infarction ${ }^{2}$. Fast and accurate risk stratification is essential in the emergency department (ED) as it allows clinicians to identify chest pain patients who are at high risk of cardiac complications and require intensive monitoring and early intervention ${ }^{4}$. Although patients frequently present with symptoms of suspected acute coronary syndrome (ACS), risk stratification remains challenging and inefficient ${ }^{5}$.

Numerous risk prediction scores have been developed that incorporate these characteristics to discriminate those patients at high risk for a major adverse cardiac event (MACE) from those with a low risk. The two most commonly used scores are the Global Registry in Acute Coronary Events ${ }^{6}$ and the Thrombolysis in Myocardial Infarction (TIMI) ${ }^{7,8}$.

A New ED Chest Pain risk stratification score; More recently, the HEART score was developed, which is a simple bedside scoring system closely following clinical reasoning. History, ECG, Age, Risk factors and Troponin, Similar to the Apgar score ${ }^{9}$, globally used to assess the need for intensive care in newborns, these five factors can be fused together. The HEART score is one tool that identifies low-risk patients who are eligible for evaluation and possible early discharge home from the ED. Large scale validation data are lacking, although current evidence suggests that patients with a HEART score of 0 to 3 have a $1 \%$ to $2 \%$ risk for major adverse cardiac events within 6 weeks of presentation ${ }^{10}$.

Year of Publication of HEART score was 2008. The HEART score for patients at the emergency room was presented by BE Backus et al., ${ }^{11}$. The HEART score contains five items (history, ECG, age, risk factors and troponin. The primary end point of the HEART score is a composite of: acute myocardial infarction (AMI), percutaneous coronary intervention (PCI), coronary artery bypass graft (CABG)surgery and death, all occurring within 6 weeks, together called MACE. These outcomes are typically related to an ACS and therefore considered indirect proof of the diagnosis ${ }^{8}$.

In this prospective cohort study of an unselected population of patients with chest pain presenting to an emergency department in Mashhad- Emam Reza hospital - we aimed to evaluate efficacy of HEART score in prediction of 30 days major advanced cardiac events (MACE) in these patients.

\section{MATERIALANDMETHODS}

This single-center prospective cohort study contained all adult patients presenting with acute chest pain to the ED of the Emam Reza Hospital, Mashhad, Iran during a 6-month study period (from September 2015 until February 2016). Patients with chest pain and significant ST-segment elevation on the ECG during transportation in the ambulance were immediately taken to the coronary intervention room. Therefore, patients with STelevation acute myocardial infarction (STEMI) and who presenting with only syncope, shortness of breath, dyspnea, palpitations or atypical complaints like fatigue, nausea or dizziness and traumatic chest pain and other diagnosis rather than ACS after evaluation, were not enrolled in the study. 
The standardized data collecting form had been completed before diagnostic testing for each patient with chest pain arrived in ED and under Triage (ESI 5 levels) referred to cardiac part of ED. This form consisted of demographic data, the HEART score and its five component sub scores (history, ECG, age, number of risk factors and troponin), and Finally 30-day Follow-up including: Alive, reaching Endpoints and Non Cardiac Death. Endpoints in this study were acute myocardial infarction (AMI), percutaneous coronary intervention (PCI), coronary artery bypass graft (CABG) and Cardiac Death). During the collection of data, admitted patients treated as usual (study was observational only).

Predictors of HEART score were scored based on Table 1. Total number of points for all parameters from 0 to 10 was noted as the HEART score for each patient. End point in this study was a composite of: AMI (Acute Myocardial Infarction), PCI (Percutaneous Coronary Intervention), CABG (Coronary Artery Bypass Graft) surgery, and death, all occurring within 30 days, together called Major Adverse Cardiac Events (MACE).

Statistical analysis was performed according to the SPSS Software (version 16.0).

\section{RESULTS}

During the study period, from September 2015 until February 2016, a total of 110 patients with acute chest pain were admitted to the emergency room after Triage and 10 of them were omitted from the study due to exclusion criteria.

Table 1. Scoring of predictors of HEART score

\begin{tabular}{|c|c|c|}
\hline \multicolumn{2}{|l|}{ Heart Score } & Points \\
\hline \multirow[t]{3}{*}{ History } & Highly Suspicious & 2 \\
\hline & Moderately Suspicious & 1 \\
\hline & Slightly Suspicious & 0 \\
\hline \multirow[t]{4}{*}{ ECG } & Significant ST-depression & 2 \\
\hline & Non-significant & \\
\hline & repolarization abnormalities & 1 \\
\hline & Normal & 0 \\
\hline \multirow[t]{3}{*}{ Age } & $\geq 65$ & 2 \\
\hline & $45-65$ & 1 \\
\hline & $\leq 45$ & 0 \\
\hline \multirow[t]{3}{*}{ Risk factors } & 3 or more risk factors & 2 \\
\hline & 1-2 risk factors & 1 \\
\hline & No risk factors & 0 \\
\hline \multirow[t]{3}{*}{ Troponin } & $\geq 3 x$ normal limit & 2 \\
\hline & 1-3x normal limit & 1 \\
\hline & $\leq$ normal limit & 0 \\
\hline
\end{tabular}

Table 2. Patient characteristics in this study

\begin{tabular}{|c|c|c|c|c|c|}
\hline \multirow[t]{2}{*}{ Character } & \multirow[t]{2}{*}{$\mathrm{N}$} & \multirow[t]{2}{*}{ Percent } & \multicolumn{2}{|c|}{ End point } & \multirow[b]{2}{*}{ P-value } \\
\hline & & & $\begin{array}{l}\text { Without End } \\
\text { Point }(\mathrm{N}=76)\end{array}$ & $\begin{array}{l}\text { With End Point } \\
\text { (MACE) }(\mathrm{N}=24)\end{array}$ & \\
\hline Age (Mean [SD]) & $60.85 \pm 14.09$ & $65.17 \pm 14.37$ & $59.49 \pm 13.82$ & 0.001 & \\
\hline Male Gender & 57 & $57 \%$ & $45(78.94 \%)$ & $12(21.05 \%)$ & 0.278 \\
\hline Female Gender & 43 & $43 \%$ & $31(72.09 \%)$ & $12(27.90 \%)$ & \\
\hline Diabetes Mellitus & 55 & $55 \%$ & $50(65.57 \%)$ & $5(20.83 \%)$ & 0.163 \\
\hline Smoking & 23 & $23 \%$ & $18(23.68 \%)$ & $5(20.83 \%)$ & 0.506 \\
\hline Hypercholesterolemia & 29 & $29 \%$ & $25(32.89 \%)$ & $4(16.66 \%)$ & 0.100 \\
\hline hypertension & 56 & $56 \%$ & $40(52.63 \%)$ & $16(66.66 \%)$ & 0.166 \\
\hline $\begin{array}{l}\text { Family History of coronary } \\
\text { artery disease }\end{array}$ & 22 & $22 \%$ & $17(22.36 \%)$ & $5(20.83 \%)$ & 0.560 \\
\hline Obesity (BMI>30) & 14 & $14 \%$ & $13(17.10 \%)$ & $1(4.16 \%)$ & 0.099 \\
\hline History Of AMI & 28 & $28 \%$ & $19(25 \%)$ & $9(37.5 \%)$ & 0.176 \\
\hline $\begin{array}{l}\text { History Of Revascularization } \\
\text { (PCI or CABG) }\end{array}$ & 15 & $15 \%$ & $12(15.78 \%)$ & $3(12.5 \%)$ & \\
\hline $\begin{array}{l}\text { History Of Stroke } \\
\text { History Of Peripheral }\end{array}$ & 1 & $1 \%$ & 0 & 1 & 0.240 \\
\hline Arterial Disease & 0 & $0 \%$ & 0 & 0 & - \\
\hline
\end{tabular}

$\mathrm{SD}=$ Standard Division, BMI $=$ Body Mass Index, PCI= Percutaneous Coronary Intervention CABG= Coronary Artery Bypass Graft, AMI= Acute Myocardial Infarction 
Table 3. Gender distribution in patients without the endpoint (Alive) and with MACE (AMI, Revascularization and death)

\begin{tabular}{|c|c|c|c|c|c|}
\hline \multirow[b]{2}{*}{ Gender } & \multirow{2}{*}{$\begin{array}{c}\text { Without End Point } \\
\text { Alive }\end{array}$} & \multicolumn{4}{|c|}{ With End Point (MACE) } \\
\hline & & AMI & PCI & CABG & Death \\
\hline Male & 45 (78.93\%) & $10(17.54 \%)$ & $0(0 \%)$ & $1(1.75 \%)$ & $1(1.75 \%)$ \\
\hline Female & 31 (72.09\%) & $8(18.60 \%)$ & $2(4.65 \%)$ & $0(0 \%)$ & $2(4.65 \%)$ \\
\hline
\end{tabular}

Table 4. The numerical distribution of the HEART score's five elements in the groups with or without endpoints HEART score

\begin{tabular}{|c|c|c|c|c|c|c|c|}
\hline \multirow[b]{2}{*}{ Points } & \multicolumn{3}{|c|}{ No endpoint reached $(\mathrm{N}=76)$} & \multicolumn{3}{|c|}{ One or more endpoints reached $(\mathrm{N}=24)$} & \multirow{2}{*}{$\begin{array}{r}\text { P-value } \\
0.337\end{array}$} \\
\hline & 0 & 1 & 2 & 0 & 1 & 2 & \\
\hline \multirow{2}{*}{$\begin{array}{l}\text { History } \\
\text { ECG }\end{array}$} & $0(0 \%)$ & $27(35.52 \%)$ & $49(64.47 \%)$ & $0(0 \%)$ & $7(29.16 \%)$ & $17(70.38 \%)$ & 0.531 \\
\hline & $\begin{array}{c}12 \\
(15.78 \%)\end{array}$ & $\begin{array}{c}37 \\
(48.68 \%)\end{array}$ & $\begin{array}{c}27 \\
(35.52 \%)\end{array}$ & $\begin{array}{c}2 \\
(8.33 \%)\end{array}$ & $\begin{array}{c}11 \\
(45.83 \%)\end{array}$ & $\begin{array}{c}11 \\
(45.83 \%)\end{array}$ & 0.032 \\
\hline Age & $\begin{array}{c}9 \\
(11.84 \%)\end{array}$ & $\begin{array}{c}38 \\
(50.0 \%)\end{array}$ & $\begin{array}{c}29 \\
(38.15 \%)\end{array}$ & $\begin{array}{c}3 \\
(12.5 \%)\end{array}$ & $\begin{array}{c}5 \\
(20.83 \%)\end{array}$ & $\begin{array}{c}16 \\
(66.66 \%)\end{array}$ & 0.807 \\
\hline Risk factors & $\begin{array}{c}9 \\
(11.84 \%)\end{array}$ & $\begin{array}{c}38 \\
(50.0 \%)\end{array}$ & $\begin{array}{c}29 \\
(38.15 \%)\end{array}$ & $\begin{array}{c}4 \\
(16.66 \%)\end{array}$ & $\begin{array}{c}8 \\
(33.33 \%)\end{array}$ & $\begin{array}{c}12 \\
(50.0 \%)\end{array}$ & 0.000 \\
\hline \multirow[t]{2}{*}{ Troponin } & $\begin{array}{c}75 \\
(98.68 \%)\end{array}$ & 0 & $\begin{array}{c}1 \\
(1.31 \%)\end{array}$ & $\begin{array}{c}7 \\
(29.16 \%)\end{array}$ & $\begin{array}{c}2 \\
(8.33 \%)\end{array}$ & $\begin{array}{c}15 \\
(62.5 \%)\end{array}$ & 0.000 \\
\hline & (average \pm & & $5.42 \pm 1.659$ & & & $7.42 \pm 1.55$ & \\
\hline
\end{tabular}

Maximum age was 88, Minimum 23, Mean age 60.85 \pm 14.09 . All patients characteristics in this study are also presented in Table 2 . It is notable that the risk profile of patients with and without the combined endpoint of AMI, revascularisation or death are also shown in this table.

Frequency and percent for each points of HEART Score in this study, gender distribution and mean (SD) for each gender are presented in Figure 1.

After 30-day follow-up, a total of 24 patients (24\%) reached one or more endpoints (Male12, Female 12). An AMI was diagnosed in 18 patients (18\%), 2 patients (2\%) underwent percutaneous coronary intervention (PCI), One (1\%) had coronary artery bypass graft (CABG) surgery and 3(3\%) died. All endpoints occurred within a time frame of 30 days. (Table 3 )

Distribution of the five predefined elements of the HEART score in the patient groups with and without endpoint of AMI, revascularisation or death(MACE) were measured in this study. The results for each parameter are shown in Table 4 . The 5 predefined elements of the
HEART score for chest pain patients and the occurrence of end points(MACE) were evaluated. Age and troponin were independent predictors of the combined end point in both gender (Age $\mathrm{P}=0.032$ and Tpi $\mathrm{P}=0.000$ ). The average HEART score in the no end point group was 5.42 and in the patients with at least one end point was 7.42 $(\mathrm{P}=0.000)$

For evaluation of sensitivity, specifity and predictive values of HEART score, we chose two cut point: 3 and 5 point. In cut point 3 sensitivity, specivity, and positive predictive value were measured $24 / 24+0=100 \%, 11 / 11+65=14.4 \%$ and $24 / 24+65=26.9 \%$, respectively. In cut point 5 , sensitivity, specifity, and positive predictive value were also calculated $21 / 21+3=87.5 \%$, 36/36 $+40=$ $47.3 \%$, and $21 / 21+40=34.4 \%$, respectively. It shows that with increasing point of HEART score, sensitivity decrease, specifity increase and Positive predictive value increase.

The ROC curve was analyzed in this study, as well (Figure 1). Area under the curve is $0.796(>0.7)$ and demonstrate stronger evidence for 


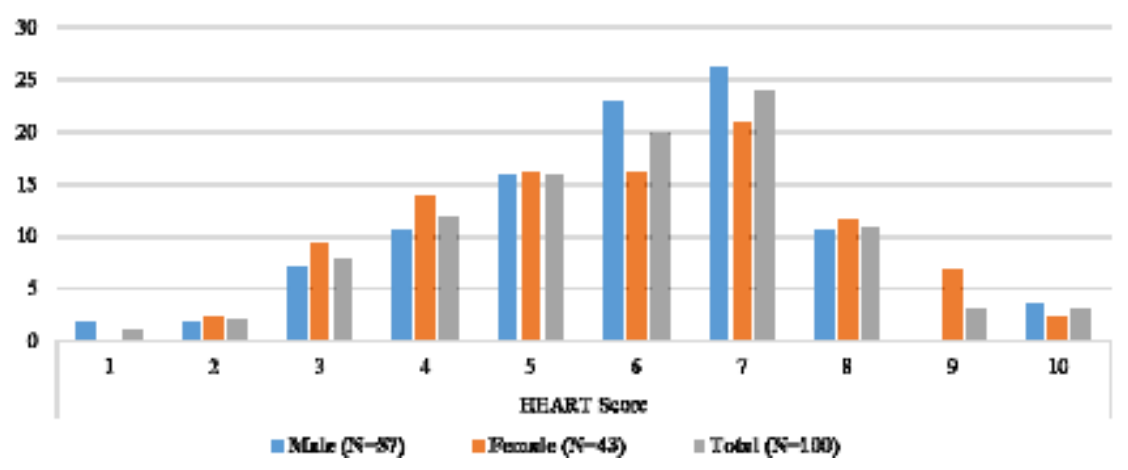

Fig. 1. Frequency and percent for each points of HEART Score in this study with gender distribution and mean (SD) for each gender

ROC Curve

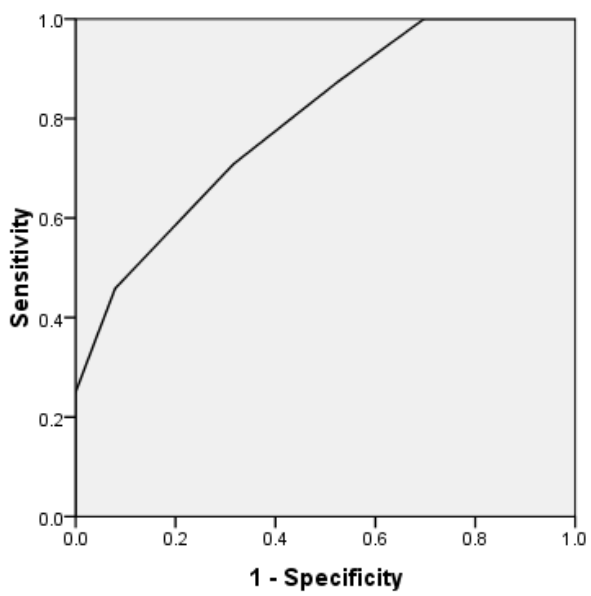

Fig. 2. ROC Curve

an end point (MACE) with higher HEART score. HEART score has at least one tie between the positive actual state group and the negative actual state group.

\section{DISCUSSION}

In our study, we demonstrate compression of HEART score in the two patient groups with and without reaching an endpoint of AMI, revascularisation or death (MACE), after 30days follow up, so indirectly evaluate diagnostic accuracy of HEART score for ACS in a population of patients with chest pain in the ED, like previous studies, we placed patients into three groups low, intermediate and high-risk groups for clinically important irreversible adverse cardiac events (MACE).

The obtained results of our study confirmed that $11 \%$ of total patients was in lowrisk group (HEART score $0-3$ ) and had $0 \%$ chance for reaching an endpoint (MACE), lower in our study compared with previous studies $2.5 \%{ }^{2}$, $0.99 \%{ }^{12}$ and $1.7 \%{ }^{13}$. Based on our results, $48 \%$ of total patients was also in intermediate-risk group (HEART score 4-6) and had $14.58 \%$ chance for reaching an endpoint (MACE), compared with previous studies, the frequency of patients had chance to reach endpoint in this group were $20.3 \%^{2}, 11.6 \%{ }^{12}$ and $16.6 \%{ }^{13}$. The results of this study showed $17 \%$ of total patients was in highrisk group (HEART score 7-10) and had 41.46\% chance for reaching an endpoint (MACE), lower in our study compared with previous studies $72 \%{ }^{2}$, $65.2 \%{ }^{12}$ and $50.1 \%{ }^{13}$.

HEART score (average \pm SD) in the two patient groups with and without reaching an endpoint was 7.42 \pm 1.55 and $5.42 \pm 1,659(\mathrm{P}=0.001)$. in comparison to the other previous studies it can be concluded both HEART score of this study are higher than others. These factors had been estimated $6.51 \pm 1.84$ and $3.71 \pm 1.83$ [2], $7.2 \pm 1.7$ and $3.8 \pm 1.9$ [12], 6.54 \pm 1.7 and $3.96 \pm 2$ [13] (all of them $\mathrm{P}=0.001$ ) respectively in other studies. It can be mentioned age (Mean[SD]) was 60.85 \pm 14.09 , lower in our study compared with previous study $61.2 \pm 15.4[2]$.

Based on our results age and troponin were independent predictors of the combined end point in both gender (Age $\mathrm{P}=0.032$ and Tpi $\mathrm{P}=0.000$ ). 
Six et al. (2008) showed that patient history, ECG abnormalities and elevated troponin values $(\mathrm{P}<0.001)$ could be independent predictors ${ }^{2} .2$ years later, Backus et al also confirmed the pervious results ${ }^{12}$. In other study, it had been indicated that History, ECG, Age, Risk Factors and Troponin $(p=0.000)$ are independent predictors of the combined end point ${ }^{13}$.

Negative predictive value of a low HEART score (0-3) was $100 \%$, higher in our study compared with previous studies which were $94 \%{ }^{8}$ and $98 \%{ }^{14}$.

In our study with increasing point of HEART score: sensitivity decrease, specifity increase and Positive predictive value increase. High sensitivities for ED chest pain risk stratification strategy often come at the expense of identifying patients for early discharge.

Several other risk scores for ACS have been published. Most highly regarded are the PURSUIT $^{15}$, GRACE ${ }^{16}$, and TIMI ${ }^{17}$ scores. Despite the firm scientific foundations and the guideline recommendations of these 3 scoring systems, none is widely applied in clinical practice. These scoring systems focus primarily on recognizing high-risk patients in a hospitalized population and show less of an interest in differentiation within most of lowrisk patients. for example, risk of MACE in lowest point of TIMI score ( 0 point) is $5 \%$.

\section{CONCLUSION}

HEART score of patient is calculate as soon as the first Tpi measurement ready. The HEART score helps in making accurate decisions at the emergency room without the use of invasive procedure. The HEART score is an easy, quick and reliable predictor of outcome in chest pain patients and therefore can be used for triage.

It also facilitates communication between doctors, especially when discussing the use of limited resources for acute chest pain patients. In this conditions who have higher HEART score points (for example HEART Score point 3, 5 and 8), may choose easier. This analysis suggests that HEART score can identify ED patients with acute chest pain for early discharge, as attention to high risk patients for admission for clinical observation, appropriate treatment including noninvasive testing and/or invasive strategies.

\section{REFERENCES}

1. Braunwald E: Unstable angina and non-ST elevation myocardial infarction. American journal of respiratory and critical care medicine 2012; 185: 924-932.

2. Six A, Backus B, Kelder J: Chest pain in the emergency room: value of the HEART score. Netherlands Heart Journal 2008; 16:191-196.

3. Hirsch A, Windhausen F, Tijssen JG, Verheugt FW, Cornel JH, de Winter RJ, Investigators IvCTiUcS: Long-term outcome after an early invasive versus selective invasive treatment strategy in patients with non-ST-elevation acute coronary syndrome and elevated cardiac troponin $\mathrm{T}$ (the ICTUS trial): a follow-up study. The Lancet 2007; 369: 827-835.

4. Marx J, Walls R, Hockberger R: Rosen’s Emergency Medicine-Concepts and Clinical Practice. Elsevier Health Sciences; 2013.

5. Mahler SA, Miller CD, Hollander JE, Nagurney JT, Birkhahn R, Singer AJ, Shapiro NI, Glynn T, Nowak R, Safdar B: Identifying patients for early discharge: performance of decision rules among patients with acute chest pain. International journal of cardiology 2013; 168: 795-802.

6. Fox KA, Eagle KA, Gore JM, Steg PG, Anderson F: The global registry of acute coronary events, 1999 to 2009-GRACE. Heart 2010:hrt. 2009. 190827.

7. Lee TH, Goldman L: Evaluation of the patient with acute chest pain. New England Journal of Medicine 2000; 342:1187-1195.

8. Visser A, Wolthuis A, Breedveld R, ter Avest E: HEART score and clinical gestalt have similar diagnostic accuracy for diagnosing ACS in an unselected population of patients with chest pain presenting in the ED. Emergency Medicine Journal :emermed-2014-203798.

9. Apgar V: A proposal for a new method of evaluation of the newborn. Classic Papers in Critical Care 1952; 32: 97.

10. Dooley-Hash S: Tintinalli’s Emergency Medicine: A Comprehensive Study Guide. JAMA 2011; 306: 100-100.

11. Backus B, Six A, Kelder J, Mast T, Van den Akker F, Doevendans P: The HEART score for chest pain patients at the emergency room. European Heart Journal 2009; 30: 312.

12. Backus BE, Six AJ, Kelder JC, Mast TP, van den Akker F, Mast EG, Monnink SH, van Tooren $\mathrm{RM}$, Doevendans PA: Chest pain in the emergency room: a multicenter validation of the HEART Score. Critical pathways in cardiology 
2010, 9:164-169.

13. Backus B, Six A, Kelder J, Bosschaert M, Mast E, Mosterd A, Veldkamp R, Wardeh A, Tio R, Braam R: A prospective validation of the HEART score for chest pain patients at the emergency department. International journal of cardiology 2013; 168: 2153-2158.

14. Poldervaart JM, Reitsma JB, Koffijberg H, Backus BE, Six AJ, Doevendans PA, Hoes AW: The impact of the HEART risk score in the early assessment of patients with acute chest pain: design of a stepped wedge, cluster randomised trial. BMC cardiovascular disorders 2013; 13: 1.

15. Granger CB, Goldberg RJ, Dabbous O, Pieper KS, Eagle KA, Cannon CP, Van de Werf F,
Avezum A, Goodman SG, Flather MD: Predictors of hospital mortality in the global registry of acute coronary events. Archives of internal medicine 2003; 163: 2345-2353.

16. Fox KA, Dabbous OH, Goldberg RJ, Pieper KS, Eagle KA, Van de Werf F, Avezum Á, Goodman SG, Flather MD, Anderson FA: Prediction of risk of death and myocardial infarction in the six months after presentation with acute coronary syndrome: prospective multinational observational study (GRACE). BMJ 2006; 333:1091.

17. de Araújo Gonçalves P, Ferreira J, Aguiar C, Seabra-Gomes R: TIMI, PURSUIT, and GRACE risk scores: sustained prognostic value and interaction with revascularization in NSTE ACS. European heart journal 2005; 26:865-872. 